\title{
UM DEBATE SOBRE FEMINISMOS DECOLONIAIS E SUAS REPERCUSSÕES PARA PESQUISAS EM POVOS INDÍGENAS NO BRASIL
}

\author{
A DEBATE ABOUT DECOLONIAL FEMINISMS AND ITS REPERCUSSIONS FOR THE RESEARCH ON INDIGENOUS \\ PEOPLES IN BRAZIL
}

\section{RESUMO}

Este texto procura apresentar um debate sobre os feminismos decoloniais, além da discussão acadêmica sobre a colonialidade. Meu objetivo é indicar caminhos possíveis para pesquisadorxs interessadxs nas chaves decoloniais, mas insatisfeitxs com suas limitações quando se deparam com situações empíricas. Desta forma, apresentarei de maneira geral o pensamento descolonial para trazer algumas reflexões sobre a colonialidade e gênero usando dois textos de autores latino-americanos (Ochy Curiel e Breny Mendoza). No final, traço algumas possibilidades teóricas e metodológicas, à luz tanto da discussão desses textos quanto da pesquisa que desenvolvi com povos indígenas no Brasil. Meus estudos com mulheres indígenas e com o movimento LGBTIQ indígena no Brasil têm apontado, até agora, para um movimento original e radical, além das discussões descoloniais, apontando novas possibilidades além daquelas indicadas pelas discussões teóricas aqui apresentadas.

Palavras-Chave: Colonialidade. Gênero. América Latina. Sexualidade. Povos Indígenas.

\begin{abstract}
This text seeks to present a debate on decolonial feminisms, beyond to the academic discussion on Coloniality. My objective is to indicate possible ways for researchers interested in the decolonial keys but dissatisfied with its limitations when encountering empirical situations. In this way, I will present in general way the decolonial thought to bring some close reflections about coloniality and gender using two texts of Latin American authors (Ochy Curiel and Breny Mendoza). In the end, I will draw some theoretical and methodological possibilities, in light of both the discussion of these texts and the research I have developed with indigenous people in Brazil. My studies with indigenous women and to the indigenous LGBTIQ movement in Brazil have hitherto pointed to an original and radical movement beyond decolonial discussions pointing out new possibilities beyond those indicated by the theoretical discussions brought here.
\end{abstract}

Keywords: Coloniality. Gender. Latin America. Sexuality. Indigenous Peoples.

Estevão R. Fernandes

Universidade Federal de Rondônia. Doutor em Estudos Comparados sobre as Américas. E-mail: estevao@unir.br 
Recentemente a academia e os movimentos sociais latino-americanos vem encontrando nas críticas coloniais e pós-coloniais produzidas no continente um novo fôlego: autores como Quijano, Dussel, Mignolo, Lugones e Segato tem sido cada vez mais referenciados em um momento - e em espaços - nos quais palavras como "periferia", "fronteira" e "lugar de fala" têm se tornado mais frequentes. Entretanto, tais potencialidades apresentam também o risco de se terem seu potencial explicativo desgastado a partir de seus sobre usos: repentinamente, tudo é colonial, tudo é exploração, tudo é sujeição.

De fato, escrevendo de onde escrevo - da Amazônia brasileira - e trabalhando com o tema ao qual me dedico há alguns anos - sexualidades não normativas e gêneros em povos indígenas - a tentação de se trabalhar de forma incondicional com autores e autoras decoloniais é dada: as explicações a partir das quais os processos de normalização dessas categorias e dessas populações podem ser transformados em fruto, pura e simplesmente, do processo colonial, faz-se certamente presente nas análises que desenvolvo. Contudo, uma forma de sefugir dessa tentação epistemológica (e política, evidentemente, sobretudo em tempos de "guinadas [anti]-democráticas" no Brasil e na América Latina, em geral) pode ser tanto o comprometimento com os dados empíricos, históricos e sociológicos obtidos a partir das pesquisas etnográficas que desenvolvo quanto a abertura a um conjunto de pensadores e ativistas os quais não se encontram no núcleo duro dessas críticas.

Nesse sentido, algumas das leituras possíveis e potencialmente mais frutíferas para problemas referentes a feminismos indígenas, sexualidades não normativas nas Amazônias, o nascente movimento LGBTIQ indígena no Brasil, dentre outros, encontra um vasto campo para reflexões a partir de textos que colocam em xeque, eles mesmos, pressupostos vistos como dogmas pela chave decolonial. Este texto busca apresentar, brevemente, um exemplo de um debate sobre feminismos decoloniais no continente, para além da discussão sobre colonialidade, per se. Meu objetivo com este artigo é, de modo breve - sendo este texto devendo ser compreendido como um reseach note - é indicar caminhos possíveis para pesquisadores tributários dessas correntes, mas insatisfeitos com suas limitações ao se deparar com situações empíricas.

Dessa maneira, apresentarei em linhas bastantegerais o pensamento decolonial para, a seguir, esboçar algumas considerações sobre colonialidade e gênero fazendo uso de dois textos de autoras latino-americanas (Ochy Curiel e Breny Mendoza) sobre a temática. Ao final, buscarei traçar algumas considerações e possibilidades teóricas e metodológicas, a luz tanto da discussão precedente quanto, evidentemente, das pesquisas que tenho desenvolvido junto a indígenas no Brasil. 


\section{Pensamento Decolonial: Um panorama}

O conceito-chave a partir do qual damos início a esta reflexão é o de decolonialidade. Tal perspectiva amplia os objetivos do Projeto Modernidade/ Colonialidade, vindo a diferenciar-se de "Pós-Colonialismo" (pensamento normalmente ligado a nomes como Edward Saïd, Gayatri Spivak e Homi Bhabha) e de "descolonialidade" (termo ligado ao processo político de descolonizalação de países periféricos).

A decolonialidade surge ao final da década de 1990, como uma crítica aos estudos pós-coloniais, até então representados no "Grupo latino-americano de estudos subalternos”. Como Castro-Gómez e Mendieta (1998:17) chamam a atenção, essa crítica surgiria "das heranças coloniais do império britânico, sendo preciso buscar uma categorização crítica do Ocidentalismo que tenha seu locus na América Latina". De fato, essa cisão viria a chamar a atenção para a necessidade de um rompimento com as epistémes eurocêntricas: se a perspectiva da intelligentsia póscolonial em países centrais (como Bhabha, Saïd e Spivak, mencionados acima) era a de uma crítica eurocêntrica ao eurocentrismo, à decolonialidade caberia o papel de transcender epistemologicamente a epistemologia ocidental (Grosfoguel, 2008).

Dessa forma, a partir da perspectiva de que as relações de colonialidade não teriam findado com o fim do colonialismo, o pensamento decolonial buscaria denunciar a continuidade dessas formas (coloniais) de dominação, bem como atualizar processos que teriam sido assimilados e invisibilizados (Ballestrin, 2013). Dessa maneira, o pensamento subalternizado - em especial o pensamento fronteiriço (sobre o qual falaremos adiante) - passaria a ser incorporado às reflexões do grupo. A colonialidade se reproduziria em uma tripla dimensão: a do poder, do saber e do ser, mas seu fundamento estaria no descobrimento e invenção da América (Ballestrin, 2013:103).

Como escreve o próprio Mignolo, nesse sentido, decolonialidade surge como

um tipo de atividade (pensamento, giro, opção) de enfrentamento à retórica da modernidade e à lógica da colonialidade. (...) pensar decolonialmente (...) significa então embarcar em um processo de desprender-se das bases eurocentradas do conhecimento (...) e de pensar fazendo conhecimentos que iluminem as zonas obscuras e os silêncios produzidos por uma forma de saber e conhecer cujo horizonte de vida foi constituindo-se na imperialidade (Grosfoguel e Mignolo, 2008:34).

Sintetizando (e ampliando) o exposto até aqui, a partir do que escrevem Mignolo e Tlostanova (2008:111), a matriz colonial do poder vem como consequência da colonização das Américas, momento em que há mudanças radicais na história da humanidade. Em escala de orientação tais mudanças podem ser descritas em quatro esferas inter-relacionadas de organização social: (1) Nível Econômico: Apropriação 
de terras e de trabalho para produção de commodities para o mercado global. A América não foi incorporada a um sistema capitalista já existente mas, ao contrário, a economia capitalista de hoje não seria possível sem a existência da América; (2) Autoridade: Concomitante a isso, as instituições espanholas e cristãs se estabelecem de modo a controlar a autoridade - ou seja, desmantelar as formas de autoridade aqui existentes; (3) Sexualidades: $O$ controle do gênero e da sexualidade com vistas a se conformar ao controle da economia e da autoridade. A moralidade cristã, a ideia de família e superioridade patriarcal foram impostas ao mesmo tempo em que a homossexualidade foi condenada e posta ao lado do demônio; e (4) Controle do conhecimento e da subjetividade: com colégios, universidades, etc., sendo fundados, surge o controle do conhecimento e, consequentemente, da subjetividade.

Todos esses níveis da matriz colonial do poder seriam inter-relacionados e interdependentes, sendo unidos pelo racismo - não compreendido aqui como classificação dos indivíduos pela cor de sua pele, mas enquanto forma de classificálos conforme determinados padrões de humanidade. Para Mignolo, a conquista da América não teria significado somente a criação de uma nova "economia mundo", mas também como a formação do primeiro grande discurso do mundo moderno, vinculado à mentalidade aristocrática cristã de "discurso de limpeza do sangue".

Nesse sentido, no século XVI está o primeiro esquema de classificação da população mundial (cf. Castro-Gómez, 2005:53): se apenas os filhos de Noé seriam descendentes diretos de Adão, qual o estatuto antropológico dos habitantes destas terras? Para Mignolo, os novos territórios e seus povos não teriam sido vistos como ontologicamente distintos dos europeus, mas como sua prolongação natural, pertencente ao "ocidente": o ocidentalismo seria o mais antigo imaginário geopolítico do sistema-mundo moderno, a "identidade fundada na distinção étnica frente ao outro caracterizou a primeira geocultura do sistema mundo moderno colonial; esta distinção não apenas coloca[ndo] a superioridade étnica de uns homens sobre outros mas também a superioridade de algumas formas de conhecimento sobre outras (Mignolo, 2008a:59; traduzi). O imaginário europeu a partir do século XVI já não tinha espaço para a coexistência de diferentes formas de ver o mundo, mas buscava taxonomizá-las conforme uma hierarquia de tempo e de espaço.

Algumas das implicações desse choque de perspectivas para a melhor compreensão da noção de gênero serão expostas e problematizadas a seguir.

\section{Algumas palavras sobre Colonialidade e Gênero}

Tendo apresentado alguns aspectos do pensamento decolonial, buscaremos fazer algumas considerações sobre a interface entre pensamento decolonial e gênero na América Latina fazendo uso de dois textos escritos há exatamente uma década por autoras latino-americanas (Curiel, 2010; e Mendoza, 2010). Os dois textos constam da mesma coletânea, editada a partir das produções expostas no Primeiro Colóquio 
Latinoamericano Pensamiento y Práxis, realizado em Buenos Aires, entre 24 e 27 de junho de 2009. A escolha desses textos como ponto de partida de minhas reflexões não se deve tão-somente ao potencial analítico das autoras, mas também a dois outros fatores: haverem sido publicados no mesmo volume e produzidos no e para o mesmo contexto - nos possibilitando compará-los de forma mais equilibrada -; e refletirem o contexto de uma década atrás, nos dando a possibilidade de ter claros os desafios analíticos já superados até aqui, e as problemáticas ainda a serem trabalhadas.

Ambos os capítulos a serem analisados aqui constam da primeira parte da coletânea, intitulada "Hacia un pensamiento propio", e se dão a partir de discussões sobre a "produção de pensamento feminista latino-americano situado geopoliticamente, comprometido com as bases conceptuais e ao devir político do feminismo regional" (Miñoso, 2010:5).

Apresentarei a seguir um resumo dos argumentos de ambas.

\section{"Hacía la construcción de un feminismo descolonizado", de Ochy Curiel}

Em seu texto Curiel parte da pergunta

qualéo feminismoquequeremos impulsionar, viver, experimentar, como proposta transformadora e radical nos países pós-coloniais como os nossos, que surja desde nossas experiências, que nos permita questioná-las em vez de modificá-las e trocar este mundo por outro que não seja patriarcal, nem racista, nem heterossexista, nem classista?! (Curiel, 2010:69).

Na busca por uma resposta, ela analisa o conceito de descolonização apresentado como um "conceito amplo que se refere tanto a processos de independência de povos e territórios que haviam sido submetidos à dominação colonial no político, econômico, social e cultural", bem como os processos ocorridos entre 1783 e 1900 nos Estados Unidos e repúblicas latino-americanas como aqueles, ocorridos entre 1920 e 1945 no Oriente Médio, e entre 1945 e 1970 na África, Ásia, Pacífico e Caribe, a partir do qual estruturar-se-iam diversos países como unidades políticas independentes. Assim, os estudos pós-coloniais colocariam em seu foco de análise a construção do sujeito póscolonial.

Para o feminismo, a descolonização implicaria em

não apenas reconhecer a dominação histórica, econômica, política e cultural da Europa sobre os povos da América, Ásia e África, mas também as sequelas desses processos: as dependências múltiplas do Sul frente a processos culturais e políticos que tem sido produto do capitalismo, da modernidade ocidental e da colonização 
europeia, assim como os efeitos da racialização e (heteros) sexualização das relações sociais, da legitimação do pensamento único, da naturalização e da institucionalização de muitas das práticas políticas de nossos movimentos sociais. Entendemos que essas dependências se atualizam em nossa subordinação frente às políticas de desenvolvimento e das lógicas colonialistas da cooperação internacional (Curiel, 2010:70).

Sendo assim, a autora destaca que a descolonização implicaria, para algumas feministas, em uma posição epistemológica e política que criaria uma espécie de cimarronagem das práticas sociais: por este termo (no original, "cimarronaje”), a autora faria menção à rebelião, por parte de escravos (indígenas e negros; individual ou coletivamente) na América Latina, frente à opressão de seus amos, salientando assim o aspecto de autonomia implicada nessa perspectiva (descolonizada) do feminismo. Assim, Curiel apresenta às/aos leitoras/es um histórico das experiências descolonizadoras no feminismo latino-americano, com especial destaque para a ação política das lésbicas - segundo ela, o lesbianismo implicaria em uma "significação e ressignificação" que era, em si mesmo, um ato de resistência descolonizador.

Dessa forma, a autora salienta o aspecto libertador do feminismo descolonizado, a partir do qual, como discurso e prática política, "questiona, em vez de propor; que busca, em vez de encontrar; que analisa o contexto global local enquanto subjetividades produzidas por raça, classe, gênero e sexualidade dadas neste contexto, mas que se articulam frente às dinâmicas estruturais" (Curiel, 2010:71). Assim, a autora chama a atenção para o aspecto inovador implicado nessa proposta de feminismo: por meio dela se criaria uma genealogia feminista, consciente de sua história. Assim, Curiel recupera o percurso do feminismo latino-americano desde a década de 1970 e 8o (quando se questionou "a mulher" de classe média, mestiça e heterossexual enquanto sujeito do feminismo), passando pelos anos 1990, momento em que parte das feministas críticas e radicais (dentre as quais a própria autora) assumiam-se como autônomas frente ao

processo de institucionalização expressa na onguização, na preparação e traçados das conferências mundiais organizadas pela ONU que definia as prioridades do movimento frente à intromissão do Banco Mundial e AID nas ações do movimento feminista, frente à cooptação de muitas feministas por parte dos Estados, governos e partidos, frente à dependência ideológica e econômica da cooperação internacional, tudo tendo altos custos para o feminismo ao perder-se boa parte de seus postulados políticos mais éticos e revolucionários (Curiel, 2010:73).

Assim, a autora cita diversas experiências na América Latina de movimentos feministas que poriam em xeque a dependência dessas instituições, a partir de uma proposta descolonizadora e transformadora, bem como em relação à produção 
de conhecimento. Entretanto, a produção da América Latina e Caribe ainda é escassa, se comparada com o feminismo europeu e norte-americano, ainda que haja produções importantes na área - tanto no âmbito acadêmico como a partir do próprio movimento. Contudo, como parte desta produção é vista como "ativista" e inadequada para a Academia, as referências para as feministas latino-americanas acabam sendo teorias e conceitos produzidos na Europa e América do Norte.

Segue a autora:

Realmente se tem descolonizado o pensamento e a teoria feminista latino-americana? Me atrevo a dizer quase um enfático não, com algumas exceções. Por mais que conheçamos o processo de colonização histórica e que sempre reajamos diante dele pela perspectiva da economia política, seguimos pensando que estamos privadas de algo, aquilo que nos falta para nos convertermos em europeias ou norte-americanas (Curiel, 2010:74).

Nesse sentido, Curiel chama a atenção para a inexistência, na América Latina, de um latinoamericanismo (em paralelo ao Orientalismo, conforme a análise de Edward Said), como modo de perceber-se "os modos de produção de um discurso de dominação sobre o feminismo latino-americano feito por feministas europeias e norte-americanas. [...] No máximo encontramos 'algumas' feministas que extraem matéria prima intelectual para a produção acadêmica europeia que não impacta além de objetivos pessoais, se esses forem definidos pela solidariedade internacional" (idem). O feminismo, como proposta de emancipação, teria produzido a crise do sujeito, mas sem conseguir livrá-lo totalmente da lógica europeia e masculina.

Assim, o pensamento feminista latino-americano caracterizar-se-ia por ser subalterno frente ao conhecimento (e práticas) provenientes da Europa e Estados Unidos, sendo essa subalternidade "atravessada indiscutivelmente por estruturas de poder que se estabeleceram historicamente por meio dos processos de colonização", possíveis de serem superadas a partir da superação do "binarismo entre teoria e prática, pois potencializaria a geração de teorias distintas, particulares, que muito podem contribuir para realmente descentrar o sujeito euronorcêntrico e a subalternidade que o mesmo feminismo latino-americano produz em seu interior" (Curiel, 2010:7576). Assim, a autora concluiu seu texto propondo a superação da compreensão de nossas experiências (latino-americanas) através do olhar imperial europeu e norteamericano, que tende a definir o "resto do mundo como o outro incivilizado, natural, irracional e falso". 


\section{"La epistemologia del sur, la colonialidad del género y el feminismo latinoamericano", de Breny Mendoza}

Mendoza era, à época da organização da coletânea, Associate Professor of Gender and Women's Studies na Universidade do Estado da Califórnia, em Northridge tendo estudado o surgimento e formação histórica do movimento feminista em Honduras, assim, como a questão da formação das nações latino-americanas a partir das ideologias hegemônicas de raça, classe, gênero e sexualidade. (Miñoso, 2010:305306).

O texto divide-se em cinco partes.

Na primeira parte ("Introdução") a autora aponta que no atual contexto latinoamericano a vanguarda "movimentista" são os movimentos indígenas, como atores que "tem o privilégio de operar com uma nova racionalidade política baseada em sua alteridade e em sua revolta contra a colonialidade do poder que rege nossas sociedades desde sua submissão ao poder imperial do Ocidente, em 1492" (Mendoza, 2010:19). Nesse contexto, em que surgem outros paradigmas, a autora se propõe a refletir sobre esses novos conhecimentos latino-americanos, que anunciam "a si mesmos como uma resposta alternativa largamente esperada através de cinco séculos de colonização ao conhecimento eurocentrado e masculino. Esses conhecimentos se autodefinem como trans-modernos, trans-capitalistas, trans-ocidentais e ocasionalmente como feministas" (Mendoza, 2010:20). Assim, a análise desses novos conhecimentos, latino-americanos, se pautará por três questionamentos, apresentados pela autora: (1) quão longe chega o novo "conhecimento outro" latino-americano em sua inclusão do pensamento feminista e da questão de gênero?; (2) Como se pode articular o feminismo e o gênero nessa nova "epistemologia do sul"; e (3) que lugar ocupam as feministas latino-americanas no surgimento e constituição da epistemologia do sul e qual pode ser seu aporte? (idem)

Após indicar essas perguntas, Mendoza dá início à segunda parte de seu texto ("O novo ethos masculino na epistemologia do sul”). Nesta etapa de suas reflexões, a autora aponta a atual centralidade que a crítica latino-americana sobre modernidade e colonialidade alcança, ainda que tal corrente apresente, se pensada a partir de uma ótica feminista, limitações quanto ao papel que o gênero ocupa em suas reflexões. Dessa maneira, a autora buscará apresentar uma análise de seu aparato conceitual e metodológico. Assim, ela apresentará aspectos do pensamento de Anibal Quijano e de Enrique Dussel.Com essa finalidade, Mendoza fará uso das críticas que Maria Lugones (filósofa e feminista argentina, atualmente professora na Universidade Binghamton, em Nova Iorque) faz ao trabalho de Quijano, em particular a sua perspectiva de gênero.

Dessa forma, a autora inicia a terceira parte de seu texto (intitulada "O gênero na teoria de Anibal Quijano") apresentando o conceito de "colonialidade do poder", cunhado por Quijano para 
descrever o padrão de poder que se estabelece com a coroa espanhola no século XVI na América, e que logo se estende por todo o planeta a medida que os poderes imperiais do Ocidente se revezam na subjugação dos que conhecemos hoje por pessoas do terceiro mundo: ameríndios, africanos da África, Caribe, América do Sul, Central e Norte, asiáticos, árabes e mestiços [...].Juntamente com o conceito de colonialidade do poder, Quijano introduz a "ideia de raça", que surge com o "descobrimento" e que serve para reclassificar socialmente e de forma estratificada as pessoas das colônias segundo sua relação com o cristianismo, a "pureza de sangue" e as línguas europeias (Mendoza, 2010:21).

Assim, a ideia de "raça” para Quijano é central, posto ser esse o conceito norteador e ordenador das lutas de poder e dos produtos delas derivadas: sexo, trabalho, autoridade coletiva e a subjetividade/intersubjetividade. Dessa maneira, a ideia de gênero estaria subordinada à de raça. Além disso, como vimos, o eurocentrismo também funcionaria como forma de construção de conhecimento, relegando os colonizados a "povos sem história", tomando por certo a "universalização da posição epistêmica dos europeus" (Mendoza, 2010:22).

Nesse sentido, ainda que Lugones reconheça o mérito na análise de Quijano, ela aponta o que é, ao seu ver, um erro cometido pelo sociólogo peruano: ele teria suposto que o gênero - e a sexualidade - sejam elementos estruturadores em todas as sociedades humanas: "ao supor isso aprioristicamente, Quijano aceita sem darse conta as premissas patriarcais, heterossexistas e eurocentradas que existem sobre gênero" (idem). Assim, Mendoza aponta duas autoras sobre as quais Lugones assentará sua análise: a feminista nigeriana Oyèrónkẹ Oyěwùmí e a feminista estadunidense indígena Paula Gunn Allen. Ambas trariam elementos, a partir de sociedades africanas e indígenas, respectivamente, no sentido de constatar a não existência de um princípio organizador como o gênero anterior à colonização. Além disso, aponta Lugones, a perspectiva de que o gênero seria uma categoria a priori, naturalizaria relações de gênero e heterossexualidade - por tomar como universal o dimorfismo sexual, a partir de um olhar biologizante sobre o corpo - encobrindo a forma como as mulheres do terceiro mundo experimentariam a colonização e seus efeitos, ainda hoje. Assim, ao longo do processo de colonização, "as mulheres não apenas foram racializadas mas, ao mesmo tempo, foram inventadas como 'mulheres' de conforme códigos e princípios discriminatórios de gênero ocidentais” (Mendoza, 2010:23).

Ao longo desse processo foram-se perdendo as relações igualitárias entre homens e mulheres nas sociedades colonizadas, ficando elas não mais submetidas apenas aos colonizadores, mas também aos homens colonizados, sendo este o preço que os homens colonizados teriam pago, segundo Lugones, para manter certo controle em suas sociedades, sendo que daí se originaria a indiferença dos homens ao sofrimento das mulheres do terceiro mundo. Mais que isso, às próprias mulheres 
brancas do ocidente tal processo também teria causado a invisibilidade da dominação das mulheres do terceiro mundo, dificultando a consolidação de alianças entre elas.

Neste ponto, Mendoza passa a traçar suas próprias considerações sobre as críticas de Lugones ao pensamento de Quijano, apontando algumas lacunas importantes nos escritos do peruano: sua perspectiva de invisibilidade do gênero como categoria histórica e instrumento da colonialidade do poder; a relação entre gênero e trabalho assalariado; os antecedentes históricos do feminicídio nas Américas; entre outras. Além disso, assim como Lugones, a autora aponta que a imposição de categorias raça e gênero teriam "produzido rachaduras profundas nas solidariedades possíveis entre as mulheres da metrópole e da periferia; e entre homens e mulheres da periferia", mas - segue a autora - "não devemos excluir as divisões que se dão também entre as mulheres da periferia" (Mendoza, 2010:25).

A autora vai além.

Segundo ela, fusão das categorias de raça e gênero teria também lançado as bases para configurar as noções de cidadania sobre a qual se assentam o capitalismo e a democracia liberal (uma vez que sobre tais categorias operariam relações de trabalho, participação política e direitos), de tal forma que seria possível falarse não apenas em "colonialidade de gênero" como escreve Lugones mas, também, de uma "colonialidade da democracia liberal" (Mendoza, 2010:26) - nesse sentido, Mendoza busca deixar ainda claro que haveria um pacto colateral entre homens e mulheres brancas da metrópole, sendo que, a fim de manterem seus privilégios (ao menos se comparadas às mulheres das periferias, e às indígenas, negras, latinas e migrantes, em seus países) invisibiliza-se o alto custo das contradições dos regimes liberais e democráticos do terceiro mundo - um exemplo disso, conforme a autora, é a participação e apoio de um setor do feminismo estadunidense que não apenas aceitou a ocupação de seu país ao Iraque e Afeganistão, como exigiu participar da operação militar. Assim, os casos de tortura na prisão de Abu Ghraib em 2004, por exemplo, "constituem uma nova versão da colonialidade de gênero e de sexualidade [...]: talvez pela primeira vez na história mulheres brancas estiveram à frente da cadeia de comando e exerceram diretamente torturas e humilhações sexuais contra homens da colônia" (Mendoza, 2010:28), deixando de ser apenas espectadoras. Sendo assim, há poucas chances de o sistema de gênero colonial moderno ser alvo de ataques das mulheres brancas ocidentais. Ao final desta etapa de seu texto, Mendoza lança-nos a pergunta: "Como imaginam os homens latino-americanos a dissolução do pacto secreto entre os homens da colônia?" (Mendoza, 2010:29).

Na quarta parte de seu texto ("Gênero nas Vinte teses de política de Enrique Dussel”) a autora apresenta o pensamento de Enrique Dussel, a fim de respondê-la. Esse filósofo traria, em suas 20 teses, um modelo político que se pretende o menos excludente possível, a partir do conceito de "povo" (bloco hegemônico a partir do qual a diversidade e demandas particulares devem ser negociadas), não funcionando aqui como uma categoria unitária, monolítica e uniforme. Ainda que Mendoza aponte a definição dusseliana de política como sendo demasiadamente machista, seus ideais 
éticos para a definição de uma nova política adviriam de imaginários femininos orientais e ameríndios, estabelecendo a vida como principio e fim máximo.

Chega-se assim à quinta e última parte do texto de Mendoza (intitulada "O feminismo latino-americano e a epistemologia do sul"), na qual retoma-se a pergunta lançada ao início do texto: "qual foi a contribuição das feministas latinoamericanas na construção de uma epistemologia do sul e quais poderiam ser suas contribuições"? (Mendoza, 2010:33). A autora problematiza a falta de articulação entre a teoria feminista latino-americana a partir de suas próprias experiências coloniais, sendo que mesmo Lugones baseia sua abordagem e avanços teóricos no campo em experiências norte-americanas e africanas. A autora propõe, assim, a desestabilização dos próprios discursos feministas produzidos na região, de modo a ultrapassar a dialética de poder cujos traços ainda são perceptíveis. Dessa maneira, ela propõe o reexame das próprias alusões à diversidade à luz das noções de decolonialidade de poder e decolonialidade de gênero, questionando ainda os aparatos conceituais dos feminismos metropolitanos e o pensamento proveniente do aparato de desenvolvimento (Mendoza, 2010:35). Assim, fica o desafio de desenvolver um aparato conceitual que alcance a complexidade da relação da colonialidade de gênero com as noções de raça, sexualidade e classe nas sociedades latino-americanas.

\section{Dito isso, aonde vamos?}

Como indicamos no início deste artigo, a proposta decolonial vem sendo recentemente e aos poucos descoberta por pesquisadores da América Latina e, nesse movimento, vem sendo incorporada às discussões de determinados grupos cujas preocupações analíticas dizem respeito às temáticas da sexualidade e do gênero. Nesse sentido, as preocupações de Mendoza e de Curiel sintetizam relativamente bem as atuais discussões sobre gênero a partir do pensamento decolonial ao longo desta década, superando, inclusive, discussões sobre violência e patriarcado desenvolvidas pelas duas maiores referências em colonialidade do gênero (Maria Lugones e Rita Laura Segato). Fato é que a agenda proposta por Curiel e Mendoza - sobretudo de um léxico mais radical no campo dos estudos de gênero, descolados epistemicamente das categorias provenientes do "norte epistêmico" e, politicamente autônomas com relação aos feminismos ocidentais - segue como um desafio, ainda hoje.

Como vimos ao longo da primeira parte deste trabalho, o pensamento decolonial oferece, ainda, um impulso analítico com potencial criativo ainda relativamente inexplorado. Em seus próprios termos, as discussões apresentadas aqui, por mais instigantes que sejam, ainda buscam uma interlocução e partem de categorias analíticas modernas, europeias e/ou norte-americanas e estabelecidas. Nesse sentido, noções como "giro decolonial", "desprendimento epistêmico" e "fronteira" ainda não parecem ter sido incorporadas ao escopo de preocupações no 
campo do gênero pelos atores diretamente envolvidos nesses processos (indígenas, camponeses, quilombolas, ribeirinhos, comunidades tradicionais, etc.).

Dessa maneira, apesar de reconhecer a importância das contribuições das autoras trazidas aqui, elas parecem desconsiderar justamente esse aspecto fluido das relações que marcam esse espaço intersticial. Como assinala Mignolo (2008b:290) "há muitas opções além da bolha do Show de Truman", e essas opções ainda não parecem ter sido plenamente exploradas - e certamente estão longe de serem esgotadas. O que se propõe, a partir desse olhar decolonial é se voltar o olhar sobre as "feridas coloniais" (nos termos de Gloria Anzaldúa), de se buscar a "subjetividade de fronteira" (Mignolo, 2007:35), de se descolonizar epistemologicamente permitindo uma troca de experiências a partir de racionalidades e paradigmas. Trata-se de se captar justamente os espaços onde são produzidas novas formas de convívio e reflexões, marcadas por espaços de trocas e redefinições.

Na prática, isso não tem ocorrido - ao menos não é o que tenho enxergado em minhas pesquisas sobre movimentos de gênero e sexualidade em povos indígenas na Amazônia brasileira. Lanço aqui mão de algumas hipóteses como forma não de concluir este artigo, mas, ao contrário, de deixar claro o momento em que estou, em termos de investigação. Em primeiro lugar, as mulheres indígenas na Amazônia não são, enquanto "movimento social", algo que possa ser compreendido de forma homogênea. Como mencionamos anteriormente, também no Brasil ao longo dos anos 1990 o banco mundial fomentou políticas de empoderamento das mulheres indígenas resultando, na maioria das vezes, em formas de organizações indígenas cujo poder era efetivamente exercido por homens - angariarem recursos financeiros. A forma como faziam isso era, quase sempre, a partir de oficinas de parteiras tradicionais, corte e costura ou trabalhos relacionados com "a mulher", nos termos ocidentais. Poucas dessas políticas resultaram em uma maior autonomia política por parte das mulheres indígenas, não pela falta de um léxico epistêmico, como apontariam as autoras mencionadas acima, mas sobretudo pelo risco que essa maior autonomia das mulheres representava, para os homens, no tocante às demandas mais tradicionalmente encampadas pelos movimentos indígenas no país: demarcação, desenvolvimento e meio ambiente. Resumidamente, antes de serem mulheres, elas eram chamadas à responsabilidade como nativas e uma demanda específica em torno da bandeira de gênero era vista como uma divisão interna nas lutas da comunidade.

Da mesma forma, até há dois ou três anos atrás não seria possível falar em um movimento LGBTIQ+ indígena no Brasil. Indígenas cujas sexualidades fogem do padrão normativo ocidental quase sempre eram impelidos a se organizarem em torno de associações de jovens indígenas, ou a buscarem em cidades maiores e/ou próximas, um refúgio dos crescentes casos de preconceitos ocasionados, sobretudo, pela ação de igrejas neopentecostais nas aldeias. De certa maneira, o crescimento da homofobia em aldeias indígenas parece ser proporcional ao recrudescimento dos discursos conservadores no Brasil e tal ação, possivelmente, desencadeou como reação a maior organização desses jovens a partir do uso de redes sociais, de sua presença em Universidades e de discussões em fóruns nacionais de estudantes indígenas. 
Assim como no caso das mulheres indígenas, a questão da juventude e da sexualidade eram vistas (e o são, de certa forma) como maneira de dividir internamente as lutas dos movimentos indígenas. Isso faz com que tais articulações acabem gerando reflexões mais aprofundadas com relação à própria gênese do movimento indígena e de suas bandeiras tradicionais, tornando a normalização das sexualidades indígenas como parte de um processo sociológico e histórico advindo do colonialismo e da religião, um campo de discussão mais maduro, do ponto de vista das reflexões epistemológicas nos permitindo, inclusive, já indicar um queer indígena como forma de descolonização das categorias de gênero pensadas na academia.

Adianto aqui essas hipóteses, as quais venho trabalhando em alguns textos a serem publicados ao longo deste e do próximo ano - não apenas em artigos, mas em um livro a ser publicado em 2020, Queer natives in Latin America - mas os rumos que as discussões sobre decolonização do gênero parecem indicar, são mais radicais do que as propostas aqui, por Curiel e Mendonza: em primeiro lugar, parece indicar para uma incorporação desse léxico decolonial como forma de resistência ao crescente conservadorismo no Brasil. Não penso, contudo, que este rumo siga os caminhos latino-americanos, mas aqueles indicados por ativistas negras norteamericanas, como Ângela Davis, por exemplo. O feminismo brasileiro, sob a égide do conservadorismo, parece ter se apropriado da interseccionalidade muito mais do que da colonialidade. Em segundo lugar, os feminismos indígenas têm mostrado uma capacidade de ocupar espaços políticos mais amplos, como demonstram Joênia Wapixana (primeira deputada federal indígena, por Roraima) e Sônia Guajajara (ex candidata a vice-presidência pelo PSOL em 2018). Da mesma forma, o nascente movimento LGBTIQ indígena tem se apropriado de espaços academicamente relevantes e surgem, desde já, pesquisas nascentes sobre a normalização de suas próprias sexualidades em seus próprios termos.

Se há alguns anos a aposta seria trabalhar temas como suicídio e migrações envolvendo esses jovens, talvez seja o momento de perceber de que maneira esse protagonismo político das mulheres indígenas, e essa crítica queer indígena por parte da juventude nas universidades, oferece uma guinada mais radical, necessária e original do que aquele caminho apontado pelos autores citados ao longo deste texto. Talvez tenhamos aí uma chave realmente decolonial. A ver.

\section{Referências}

BALLESTRIN, Luciana. 2013. "América Latina e o giro decolonial”. Rev. Bras. Ciênc. Polít., (11): 89-117.

CASTRO-GÓMEZ, Santiago. 2005. La poscolonialidad explicada a los niños. Bogotá: Universidad del Cauca, Instituto Pensar. 
CASTRO-GÓMEZ, Santiago e Eduardo MENDIETA (eds.). 1998. Teorías sin disciplina. Latinoamericanismo, Poscolonialidad y Globalización en debate. México: Porrúa/USF.

CURIEL, Ochy. 2010. "Hacía la construcción de un feminismo descolonizado". In: MIÑOSO, Yuderkys Espinosa (coord). Aproximaciones críticas a las prácticas teóricopolíticas del feminismo latinoamericano - Vol 1: 69- 78. Buenos Aires: En la Frontera.

GROSFOGUEL, Ramón. 2007. "Descolonizando los universalismos occidentales: el pluri-versalismo transmoderno decolonial desde Aimé Césaire hasta los zapatistas", In: CASTRO-GÓMEZ, Santiago e Ramon GROSFOGUEL (Orgs.) El giro decolonial: reflexiones para uma diversidad epistêmica más allá del capitalismo global. Bogotá: Siglo del Hombre Editores, Universidad Central, Instituto de Estudios Sociales Contemporáneos, Pontificia Universidad Javeriana, Instituto Pensar.

. 2008. "Para descolonizar os estudos de economia política e os estudos pós-coloniais: transmodernidade, pensamento de fronteira e colonialidade global". Revista Crítica de Ciências Sociais (80):115-147.

GROSFOGUEL, Ramón e Walter MIGNOLO. 2008. “Intervenciones Descoloniales: una breve introducción". Tabula Rasa (9): 29-38.

MENDOZA, Breny. 2010. "La epistemologia del sur, la colonialidad del género y el feminismo latinoamericano". In: MIÑOSO, Yuderkys Espinosa (coord). Aproximaciones críticas a las prácticas teórico-políticas del feminismo latinoamericano - Vol.1: 19-36, Buenos Aires: En la Frontera

MIGNOLO, Walter. 2008a. "The Geopolitics of Knowledge and the Colonial Difference". In: Mabel MORAÑA, Enrique DUSSEL, Carlos JÁUREGUI (Eds.) Coloniality at Large. Latin America and the Postcolonial Debate, Latin America Otherwise. pp. 225-258. Durham: Duke University Press.

2008b. "Desobediência epistêmica": A opção descolonial e o significado de identidade em política". Cadernos de letras da UFF (34):287-324.

MIGNOLO, Walter e Madina TLOSTANOVA. 2008. "The Logic of Coloniality and the Limits of Postcoloniality”. In: HAWLEY, John, Revathi KRISHNASWAMY (Eds.) The Postcolonial and the Global. Minneapolis: University of Minnessota Press.

MIÑOSO, Yuderkys Espinosa (coord). 2010. Aproximaciones críticas a las prácticas teórico-políticas del feminismo latinoamericano - Vol. 1. Buenos Aires: En la Frontera. 